\title{
Use of Smartphone Applications in Herbal Poisoning
}

\author{
(D) Mehmet Esat Ferhatlar, (D) Vahide Aslankoç, (D) Neşe Kaya
}

University of Health Sciences Turkey, İstanbul Okmeydanı Training and Research Hospital, Cinic of Emergency Medicine, Istanbul, Turkey

Keywords: Plant, intoxication, smartphone, datura stramonium, pipe weed, poisoning

\section{Dear Editor,}

In November 2019, many patients applied to the Emergency Department of Okmeydanı Training and Research Hospital, with various complaints after eating spinach. Patients' complaints included hallucination, speech disorder, dry mouth, confusion, and agitation. Meanwhile, some cities such as Ankara, Edirne, and Tekirdağ were reported to have had similar cases. The common features of all the patients were that they had eaten a spinach-like vegetable (1). In the physical examination of the patients, there were anticholinergic findings such as tachycardia, mydriasis, flushing. Therefore, patient relatives were asked to bring the sample of the plant that the patients had eaten. Photos of the plant samples brought were uploaded to a plant recognition application called PlantSnap ${ }^{\circledR}$. Using plant recognition application, it was determined that our patients were poisoned not from spinach but from the plant called datura stramonium, which is known as pipe grass among the people. This plant grows in the harvest period of spinach and is very similar to spinach.

Approximately 40 thousand tons of spinach has been produced in Ankara of Turkey. This product is sold up to the Trakya region. This is the main reason why patients are reported from Ankara, Edirne, and Tekirdağ. We thought that this poisoning was due to Datura stramonium possibly the spinach being mixed into the during harvest.

The chemical structure of the plant named Datura stramonium contains tropane group alkaloids, atropine, hyoscyamine, and scopolamine, which are responsible for hallucinogenic effects and anticholinergic findings in our patients (2). Supportive treatments, gastrointestinal decontamination therapy, and physostigmine were given to our patients according to their clinical status, and all of our patients were discharged healthily.

Smartphone applications have started to take place more frequently in our lives recently. Health-related practices, in particular, attract the attention of both healthcare professionals and others. Such practices also facilitate some interventions for our patients. For example, Kalkan and Yigit (3) argued that patients would be referred with Whatsapp ${ }^{\circledR}$, which is a smartphone application in their studies. PlantSnap ${ }^{\circledR}$ is an application that interprets the photograph of the plant and gives information about the plant with an accuracy of up to $90 \%$. This application makes the researched plant compared to the plants it has previously recorded in its own database. By using this application, we found out which plant our patients were poisoned and made appropriate interventions.

Although this is the opinion of a biologist who is sure in such poisonings, we think that such applications will be useful in the emergency room. We think that smartphone applications such as PlantSnap ${ }^{\circledR}$ can be used, especially in herbal poisoning requiring rapid diagnosis and treatment if the poisoning plant can be reached.

Mobile health is a rapidly developing field, and various applications can be used in the diagnosis and follow-up of patients (3). PlantSnap ${ }^{\circledR}$, etc. to diagnose and start treatment faster in poisonings with plants, plant identification applications can be used. 


\section{Ethics}

Peer-review: Internally peer-reviewed.

\section{Authorship Contributions}

Concept: M.E.F., Design: V.A., N.K., M.E.F., Data Collection or Processing: M.E.F., N.K., V.A., Analysis or Interpretation: N.K., Literature Search: V.A., Writing: V.A., M.E.F., N.K.

Conflict of Interest: No conflict of interest was declared by the authors.

Financial Disclosure: The authors declared that this study received no financial support.

\section{REFERENCES}

1. Available from: https://www.sabah.com.tr/yasam/2019/11/04/sondakika-haberi-istanbulda-ispanaktan-zehirlenme-vakalari-devamediyor

2. Ghorani-Azam A, Sepahi S, Riahi-Zanjani B, Alizadeh Ghamsari A, Mohajeri SA, Balali-Mood M. Plant toxins and acute medicinal plant poisoning in children: A systematic literature review. J Res Med Sci 2018; 23-6.

3. Kalkan A, Yigit Y. Benefits of using a smartphone in patient referral. Journal of Academic Emergency Medicine 2015;14-97. 